\title{
Effect of adjuvant trastuzumab among patients treated with anti-HER2-based neoadjuvant therapy
}

\author{
A M Gonzalez-Angulo ${ }^{1,2}$, N Parinyanitikul ${ }^{1}, \mathrm{X} \mathrm{Lei}^{3}, \mathrm{E} \mathrm{A} \mathrm{Mittendorf}{ }^{4}, \mathrm{H}$ Zhang $^{5}$, V Valero ${ }^{1}, \mathrm{~K} \mathrm{~K} \mathrm{Hunt}^{4}$, \\ G N Hortobagyi ${ }^{1}$ and M Chavez-MacGregor ${ }^{*}, 1,6$ \\ ${ }^{1}$ Department of Breast Medical Oncology at The University of Texas, MD Anderson Cancer Center, Houston, TX, USA; \\ ${ }^{2}$ Department of Systems Biology at The University of Texas, MD Anderson Cancer Center, Houston, TX, USA; ${ }^{3}$ Department of \\ Biostatistics at The University of Texas, MD Anderson Cancer Center, Houston, TX, USA; ${ }^{4}$ Department of Surgical Oncology at \\ The University of Texas, MD Anderson Cancer Center, Houston, TX, USA; ${ }^{5}$ Department of Pathology at The University of Texas, \\ MD Anderson Cancer Center, Houston, TX, USA and ${ }^{6}$ Department of Health Services Research at The University of Texas, \\ MD Anderson Cancer Center, Houston, TX, USA
}

Purpose: To study the impact of adjuvant trastuzumab among patients achieving a pathologic complete response ( $p C R$ ) after trastuzumab-based neoadjuvant systemic therapy (NST).

Patients and methods: Patients with primary HER2-positive breast cancer treated with trastuzumab-based NST were categorised according to adjuvant trastuzumab administration and PCR status. Adjuvant trastuzumab became standard of care in 2006, this was the main reason patients in our cohort did not receive adjuvant trastuzumab. Kaplan-Meier was used to estimate survival. A test for interaction between adjuvant trastuzumab and PCR was completed.

Findings: Of 589 patients, 203 (34.5\%) achieved a pCR. After surgery, 109 (18.5\%) patients in the entire cohort did not receive adjuvant trastuzumab. Among patients achieving a PCR, 31.3\% received adjuvant trastuzumab compared with $68.8 \%$ among those who did not achieve a $\mathrm{pCR}(P=0.0006)$. Among patients achieving $\mathrm{pCR}$, adjuvant trastuzumab did not further improve overall survival (OS) or relapse-free survival (RFS) ( $P=0.35$ and $P=0.93$, respectively). Any benefit of adjuvant trastuzumab in OS and RFS among patients without a $\mathrm{pCR}$ did not achieve statistical significance $(P=0.3$ and $P=0.44$, respectively).

Conclusions: In this cohort, patients treated with trastuzumab-based NST who achieved a pCR have excellent outcome regardless of whether they received adjuvant trastuzumab.

Neoadjuvant systemic therapy (NST) is commonly used to downstage the primary tumour and regional lymph nodes preoperatively, in order to increase operability and enable breastconserving surgery in patients with large primary tumours or locally advanced disease (Fisher et al, 1998; Gralow et al, 2008). NST also allows the assessment of the effectiveness of the systemic treatment by pathologic evaluation of the breast and nodes removed at surgery (Gralow et al, 2008; Cortazar et al, 2014).
A pathologic complete response (pCR) in the breast and nodes is associated with favourable survival outcomes. However, this association is stronger among patients with highly proliferative, HER2-positive breast cancers (Untch et al, 2011; Kim et al, 2013; Cortazar et al, 2014).

HER2 is overexpressed in approximately $15-25 \%$ of primary breast cancers (Wolff et al, 2013). In the neoadjuvant setting, randomised trials have shown that the use of trastuzumab-based

*Correspondence: Dr M Chavez-MacGregor; E-mail: mchavez1@mdanderson.org

Results of this study were presented in part at the 2014 American Society of Clinical Oncology, Chicago, IL, June, 2014.

Received 25 July 2014; revised 21 November 2014; accepted 6 December 2014; published online 13 January 2015 
NST increases pCR rates compared with chemotherapy alone (Buzdar et al, 2005; Gianni et al, 2014), and recent data demonstrated that dual anti-HER2 therapy combined with chemotherapy further increases pCR rates as compared with trastuzumab-based chemotherapy (Baselga et al, 2012; Gianni et al, 2012).

Although 1 year of trastuzumab therapy is considered the standard of care today, several studies have been designed to look at shorter or longer treatment times (Goldhirsch et al, 2013; Pivot et al, 2013). A recent randomised trial comparing 6 months of adjuvant trastuzumab therapy $v s 1$ year failed to show that 6 months of adjuvant trastuzumab treatment was non-inferior to 12 months (Pivot et al, 2013). The impact of adjuvant trastuzumab among patients achieving a pCR after trastuzumab-based NST is unknown. We therefore, aimed to evaluate the impact of completion of adjuvant trastuzumab according to pCR status.

\section{PATIENTS AND METHODS}

A retrospective review of the Breast Medical Oncology Institutional database at The University of Texas MD Anderson Cancer Center was performed. Women with HER2-positive primary invasive breast cancer who received trastuzumab-based NST from 2001 to 2012 were identified. Adjuvant trastuzumab became standard of care in 2006; this was the main reason patients in our cohort did not receive adjuvant trastuzumab in earlier years. Patients were classified according to whether they had received adjuvant trastuzumab or not. Data were extracted on relevant prognostic factors including year of diagnosis, age, menopausal status, race, histology, grade, lymphovascular invasion (LVI), oestrogen receptor status, progesterone receptor status, adjuvant radiation, and adjuvant endocrine therapy. pCR was defined as no evidence of invasive cancer in the breast and lymph nodes (yT0/is,N0).

Patient characteristics were tabulated and compared between the adjuvant trastuzumab $v s$ no adjuvant trastuzumab groups using Chi-square test. Overall survival (OS) was measured from the date of diagnosis to the date of death or lost to follow-up. Relapse-free survival (RFS) was measured from the date of diagnosis to the date of first documented local or distant recurrence. Patients who died before experiencing the relevant events were considered censored for RFS at their dates of last follow-up. The Kaplan-Meier product limit method was used to estimate the 5-year OS and RFS with 95\% confidence intervals (CIs) of all patients, and compared using the log-rank statistic. Cox proportional hazards models were fit to determine the association of patient and clinical characteristics with survival outcomes. Initially, a Cox proportional hazard model that included pCR, adjuvant trastuzumab and the interaction between both covariates was tested. Because of rare events in one of the groups defined by the two variables, Firth's penalised likelihood approach was applied to obtain a finite estimate for the coefficient (Firth, 1993). The profile-likelihood confidence limits for the hazard ratios (HR) are presented. Variables were included in the final Cox multivariate model based on both statistical significance and clinical relevance including adjuvant trastuzumab, pCR, race, clinical stage at presentation, hormone receptor status, and LVI, year of diagnosis and adjuvant endocrine therapy. Results are expressed in $\mathrm{HR}$ and 95\% CIs. $P$ values less than 0.05 were considered statistically significant; all tests were two-sided. Statistical analyses were carried out using SAS 9.3 (SAS Institute, Cary, NC, USA) and S-Plus 8.2 (TIBCO Software Inc., Houston, TX, USA).

\section{RESULTS}

A total of 589 women with HER2-positive breast cancer diagnosed between 2001 and 2012 were identified. Patients received NST with either PH-FECH (paclitaxel $80 \mathrm{mg} \mathrm{m}^{-2}$ intravenously weekly for 12 weeks or paclitaxel $225 \mathrm{mg} \mathrm{m}^{-2}$ intravenously over $24 \mathrm{~h}$ every 3 weeks, followed by 4 cycles of FEC-75 (5-fluorouracil $500 \mathrm{mg} \mathrm{m}^{-2}$, epirubicin $75 \mathrm{mg} \mathrm{m}^{-2}$, and cyclophosphamide $500 \mathrm{mg} \mathrm{m}^{-2}$ ) intravenously on day 1 , every 3 weeks. A loading dose of $4 \mathrm{mg} \mathrm{kg}^{-1}$ intravenously trastuzumab was given on day 1 followed by $2 \mathrm{mg} \mathrm{kg}^{-1}$ weekly, during the 24 weeks of NST). After surgery, $109(18.5 \%)$ patients did not receive adjuvant trastuzu$\mathrm{mab}$, and $480(81.5 \%)$ patients received adjuvant trastuzumab for 6 months to complete 1 year of therapy. Patient characteristics by adjuvant trastuzumab therapy are presented in Table 1 . There were no significant differences amongst clinical and pathologic factors. A total of 203 patients (34.55) achieved a pCR. Among them, $73.9 \%$ of the patients received adjuvant trastuzumab compared with $85.5 \%$ of patients not achieving a pCR $(P=0.0006)$.

At a median follow-up of 45 months, (range, 9-144 months), 38 patients $(6.5 \%)$ had died, and $61(10.4 \%)$ had experienced a recurrence. Table 2 summarises the 5-year OS and RFS estimates by patient and tumour characteristics. For the overall cohort, 5year OS and RFS were $93 \%$ and $87 \%$, respectively. The 5 -year OS estimates were $91 \%$ and $93 \%$ for patients who did not or did receive adjuvant trastuzumab $(P=0.97)$; and the 5-year RFS estimates were $92 \%$ and $85 \%$ for patients who did not or did receive adjuvant trastuzumab $(P=0.33)$, respectively. When comparing patients who did not or did achieve a pCR after NST, the 5-year OS estimates were $90 \%$ and $98 \% \quad(P=0.002)$, respectively; and the 5-year RFS estimates were $83 \%$ and $95 \%$ $(P<0.0001)$, respectively. The Kaplan-Meier estimates of OS and RFS stratified by adjuvant trastuzumab and $\mathrm{pCR}$ status are presented in Figure 1.

On multivariate analysis, there was no significant interaction between adjuvant trastuzumab and pCR on OS $(P=0.32)$ or RFS $(P=0.15)$. After adjustment for year of diagnosis, pCR, race, clinical stage at presentation, hormone receptor status, LVI and adjuvant endocrine therapy, adjuvant trastuzumab had no significant impact on $\mathrm{OS}(\mathrm{HR}=0.75 ; 95 \% \quad \mathrm{CI}=0.31-1.78$; $P=0.51)$ or $\mathrm{RFS}(\mathrm{HR}=1.10 ; 95 \% \mathrm{CI}=0.52-2.33 ; P=0.81)$. As expected, patients who achieved a pCR had a decreased risk of death $(\mathrm{HR}=0.23 ; 95 \% \mathrm{CI}=0.08-0.60 ; P=0.003)$ and recurrence $(\mathrm{HR}=0.22 ; 95 \% \mathrm{CI}=0.1-0.49 ; P=0.0002)$. In addition, black race $(\mathrm{HR}=2.07 ; 95 \% \mathrm{CI}=1.11-3.87 ; P=0.022)$, clinical stage III disease at diagnosis $(\mathrm{HR}=2.28 ; 95 \% \mathrm{CI}=1.3-3.99 ; P=0.004)$, and the presence of LVI $(\mathrm{HR}=2.28 ; 95 \% \mathrm{CI}=1.33-3.93 ; P=0.003)$ were associated with an increased risk of recurrence (Table 3 ).

\section{DISCUSSION}

This study was undertaken to evaluate the impact of completion of adjuvant trastuzumab in patients with HER2-positive disease treated at our institution according to pCR status. In this cohort of patients treated with trastuzumab-based NST, those who achieved a pCR had an excellent outcome regardless of whether they received adjuvant trastuzumab or not.

In our initial trastuzumab-based neoadjuvant study, patients received trastuzumab for only 24 weeks during chemotherapy and did not receive adjuvant trastuzumab following local therapy because adjuvant trastuzumab was, at the time, not part of the standard of care (Buzdar et al, 2007). This practice was continued until trastuzumab was approved in the adjuvant setting with the recommended duration of 1 year of treatment. To our knowledge, this is the only cohort of patients available to evaluate the impact of adjuvant trastuzumab among patients who achieved a pCR. A recently published retrospective study evaluating the outcomes of patients with HER2-positive breast cancer reported that 65 (8.4\%) of the 776 patients in the study did not receive adjuvant 
Table 1. Patient and tumour characteristics

\begin{tabular}{|c|c|c|c|c|c|c|}
\hline & \multirow{2}{*}{$\begin{array}{c}\begin{array}{c}\text { All patients } \\
(N=589)\end{array} \\
N(\%)\end{array}$} & \multicolumn{2}{|c|}{ No adjuvant trastuzumab $(N=109)$} & \multicolumn{2}{|c|}{ Adjuvant trastuzumab $(N=480$} & \multirow[b]{2}{*}{$P$-value } \\
\hline & & $N$ & $\%$ & $N$ & $\%$ & \\
\hline \multicolumn{7}{|c|}{ Year of diagnosis } \\
\hline 2001-2006 & $142(24.1 \%)$ & 80 & 73.4 & 62 & 12.9 & \\
\hline 2007-2012 & 447 (75.9\%) & 29 & 26.6 & 418 & 87.1 & $<0.0001$ \\
\hline \multicolumn{7}{|c|}{ Age (years) } \\
\hline Age $\leq 50$ & $293(49.7 \%)$ & 52 & 47.7 & 241 & 50.2 & \\
\hline Age $>50$ & $296(50.3 \%)$ & 57 & 52.3 & 239 & 49.8 & 0.64 \\
\hline \multicolumn{7}{|c|}{ Race/ethnicity } \\
\hline White & 344 (58.4\%) & 66 & 60.6 & 278 & 57.9 & \\
\hline Black & 73 (12.4\%) & 15 & 13.8 & 58 & 12.1 & \\
\hline Hispanic & 116 (19.7\%) & 20 & 18.3 & 96 & 20.0 & \\
\hline Other & $56(9.5 \%)$ & 8 & 7.3 & 48 & 10.0 & 0.78 \\
\hline \multicolumn{7}{|c|}{ Clinical stage } \\
\hline 1 & 8 (1.4\%) & 2 & 1.9 & 6 & 1.3 & \\
\hline ॥ & 293 (50.3\%) & 59 & 54.6 & 234 & 49.3 & \\
\hline III & $282(48.4 \%)$ & 47 & 43.5 & 235 & 49.5 & 0.50 \\
\hline \multicolumn{7}{|l|}{ Histology } \\
\hline Ductal & $543(92.2 \%)$ & 102 & 93.6 & 441 & 91.9 & \\
\hline Other & $46(7.8 \%)$ & 7 & 6.4 & 39 & 8.1 & 0.55 \\
\hline \multicolumn{7}{|c|}{ Nuclear grade } \\
\hline $1-2$ & $123(21.4 \%)$ & 86 & 78.9 & 366 & 78.5 & \\
\hline 3 & $452(78.6 \%)$ & 23 & 21.1 & 100 & 21.5 & 0.93 \\
\hline \multicolumn{7}{|c|}{ Lymphovascular invasion } \\
\hline Negative & $479(81.3 \%)$ & 92 & 84.4 & 387 & 80.6 & \\
\hline Positive & $110(18.7 \%)$ & 17 & 15.6 & 93 & 19.4 & 0.36 \\
\hline \multicolumn{7}{|c|}{ Hormone receptor status } \\
\hline Negative & $236(40.4 \%)$ & 51 & 46.8 & 185 & 38.9 & \\
\hline Positive & $348(59.6 \%)$ & 58 & 53.2 & 290 & 61.1 & 0.13 \\
\hline \multicolumn{7}{|c|}{ Pathologic complete response } \\
\hline No & 386 (65.5\%) & 56 & 51.4 & 330 & 68.8 & \\
\hline Yes & $203(34.5 \%)$ & 53 & 48.6 & 150 & 31.3 & 0.0006 \\
\hline \multicolumn{7}{|c|}{ Adjuvant radiation } \\
\hline No & $125(21.2 \%)$ & 24 & 22.0 & 101 & 21.0 & \\
\hline Yes & $464(78.8 \%)$ & 85 & 78.0 & 379 & 79.0 & 0.82 \\
\hline \multicolumn{7}{|c|}{ Adjuvant endocrine therapy } \\
\hline No & $301(51.1 \%)$ & 59 & 54.1 & 242 & 50.4 & \\
\hline Yes & 288 (48.9\%) & 50 & 45.9 & 238 & 49.6 & 0.48 \\
\hline
\end{tabular}

trastuzumab, however, outcomes in this group were not discussed (Takada et al, 2014).

Although the test for interaction in the analysis of our patient cohort was negative, we applied a Firth's penalised likelihood approach to obtain a finite estimate for the coefficients and the profile-likelihood confidence limits for the HR in the multivariable analysis to compensate for our limited sample size before commit to our conclusions (Firth, 1993).

Currently, there is compelling evidence from large phase III randomised clinical trials including approximately 12000 patients supporting the standard use of adjuvant trastuzumab for 1 year. On the basis of the results of the FinHER study (Joensuu et al, 2009), shorter adjuvant trastuzumab regimens are being evaluated ( 9 weeks, 3 months, and 6 months), but only one has been fully reported. Results from the PHARE trial failed to show that 6 months of trastuzumab is non-inferior to 12 months. Nevertheless, the cardiac safety profile was more favourable for the shorter treatment (Pivot et al, 2013). The results of other on-going or recently completed studies are not expected before 2015, at which time they might be less relevant given that dual anti-HER2 therapy with pertuzumab and trastuzumab is now part of the new standard of care.
As our treatment armamentarium increases, we continue to struggle to find biomarkers capable of identifying those patients with HER2-positive breast cancer who need less extensive or less complex therapies, and pCR after adequate NST may be a good surrogate. All anti-HER2-based NST studies have shown that patients who achieved a pCR at the time of surgery have an excellent prognosis and the majority are probably cured (Buzdar et al, 2007; Untch et al, 2011; Baselga et al, 2012; Bayraktar et al, 2012; Gianni et al, 2012; Buzdar et al, 2013; Cortazar et al, 2014; Gianni et al, 2014). The use of maintenance trastuzumab to complete a year of therapy is considered standard, and no data are available to support the use of pertuzumab, T-DM1, or lapatinib in the adjuvant setting; further, the neoadjuvant studies adding lapatinib and pertuzumab only used these targeted therapies in the pre-operative portion of the treatment (Baselga et al, 2012; Gianni et al, 2012). Our work is limited by its retrospective nature and limited sample size; despite including in the multivariable model important clinical variables, residual confounding cannot be excluded. Furthermore, selection bias is a potential concern because we do not have specific information on the reason a patient was prescribed further adjuvant trastuzumab or not. Our results are hypothesis-generating and need to be interpreted with 
Table 2. Survival estimates by patient characteristics

\begin{tabular}{|c|c|c|c|c|c|c|c|}
\hline & $\begin{array}{c}N \\
\text { Patients }\end{array}$ & $\begin{array}{c}N \\
\text { Events }\end{array}$ & $\begin{array}{c}5 \text {-year } \\
\text { overall survival } \\
\text { estimate }(95 \% \mathrm{Cl})\end{array}$ & $P$-value & $\begin{array}{c}N \\
\text { Events }\end{array}$ & $\begin{array}{c}5 \text {-year } \\
\text { relapse-tree survival } \\
\text { estimate }(95 \% \mathrm{Cl})\end{array}$ & $P$-value \\
\hline All patients & 589 & 38 & $0.93(0.9,0.95)$ & & 61 & $0.87(0.84,0.9)$ & \\
\hline \multicolumn{8}{|c|}{ Year of diagnosis } \\
\hline $2001-2006$ & 142 & 14 & $0.92(0.86,0.96)$ & & 19 & $0.88(0.82,0.93)$ & \\
\hline 2007-2012 & 447 & 24 & $0.93(0.89,0.95)$ & 0.60 & 42 & $0.86(0.8,0.9)$ & 0.64 \\
\hline \multicolumn{8}{|c|}{ Age (years) } \\
\hline Age $\leq 50$ & 293 & 19 & $0.93(0.88,0.96)$ & & 30 & $0.87(0.82,0.91)$ & \\
\hline Age $>50$ & 296 & 19 & $0.92(0.88,0.95)$ & 0.78 & 31 & $0.87(0.82,0.91)$ & 0.80 \\
\hline \multicolumn{8}{|c|}{ Race/ethnicity } \\
\hline White & 344 & 23 & $0.92(0.88,0.95)$ & & 33 & $0.89(0.85,0.92)$ & \\
\hline Black & 73 & 6 & $0.89(0.77,0.95)$ & & 13 & $0.72(0.55,0.84)$ & \\
\hline Hispanic & 116 & 4 & $0.98(0.92,0.99)$ & & 7 & $0.92(0.83,0.96)$ & \\
\hline Other & 56 & 5 & $0.87(0.71,0.95)$ & 0.39 & 8 & $0.84(0.71,0.92)$ & 0.03 \\
\hline \multicolumn{8}{|c|}{ Clinical stage } \\
\hline$|-| \mid$ & 301 & 17 & $0.93(0.89,0.96)$ & & 22 & $0.9(0.85,0.94)$ & \\
\hline III & 282 & 20 & $0.92(0.87,0.95)$ & 0.42 & 38 & $0.84(0.79,0.88)$ & 0.01 \\
\hline \multicolumn{8}{|l|}{ Histology } \\
\hline Ductal & 543 & 34 & $0.93(0.9,0.95)$ & & 54 & $0.88(0.84,0.91)$ & \\
\hline Other & 46 & 4 & $0.91(0.74,0.97)$ & 0.56 & 7 & $0.82(0.64,0.92)$ & 0.26 \\
\hline \multicolumn{8}{|c|}{ Nuclear grade } \\
\hline $1-2$ & 123 & 7 & $0.93(0.84,0.97)$ & & 14 & $0.86(0.76,0.92)$ & \\
\hline 3 & 452 & 30 & $0.93(0.89,0.95)$ & 0.57 & 45 & $0.88(0.84,0.91)$ & 0.71 \\
\hline \multicolumn{8}{|c|}{ Lymphovascular invasion } \\
\hline Negative & 479 & 24 & $0.94(0.91,0.96)$ & & 37 & $0.9(0.87,0.93)$ & \\
\hline Positive & 110 & 14 & $0.86(0.76,0.92)$ & 0.002 & 24 & $0.72(0.6,0.81)$ & $<0.0001$ \\
\hline \multicolumn{8}{|c|}{ Hormone receptor status } \\
\hline Negative & 236 & 18 & $0.92(0.86,0.95)$ & & 24 & $0.88(0.82,0.92)$ & \\
\hline Positive & 348 & 20 & $0.93(0.89,0.96)$ & 0.53 & 36 & $0.87(0.82,0.91)$ & 0.77 \\
\hline \multicolumn{8}{|c|}{ Pathologic complete response } \\
\hline No & 386 & 33 & $0.9(0.85,0.93)$ & & 54 & $0.83(0.78,0.87)$ & \\
\hline Yes & 203 & 5 & $0.98(0.93,0.99)$ & 0.002 & 7 & $0.95(0.9,0.98)$ & $<0.0001$ \\
\hline \multicolumn{8}{|c|}{ Adjuvant trastuzumab } \\
\hline No & 109 & 11 & $0.91(0.84,0.95)$ & & 12 & $0.92(0.85,0.96)$ & \\
\hline Yes & 480 & 27 & $0.93(0.9,0.95)$ & 0.97 & 49 & $0.85(0.8,0.89)$ & 0.33 \\
\hline \multicolumn{8}{|c|}{ Adjuvant radiation } \\
\hline No & 125 & 8 & $0.94(0.86,0.97)$ & & 10 & $0.89(0.79,0.95)$ & \\
\hline Yes & 464 & 30 & $0.92(0.89,0.95)$ & 0.69 & 51 & $0.87(0.83,0.9)$ & 0.63 \\
\hline \multicolumn{8}{|c|}{ Adjuvant endocrine therapy } \\
\hline No & 301 & 23 & $0.91(0.87,0.94)$ & & 31 & $0.87(0.82,0.91)$ & \\
\hline Yes & 288 & 15 & $0.94(0.89,0.96)$ & 0.17 & 30 & $0.87(0.82,0.91)$ & 0.84 \\
\hline
\end{tabular}

A

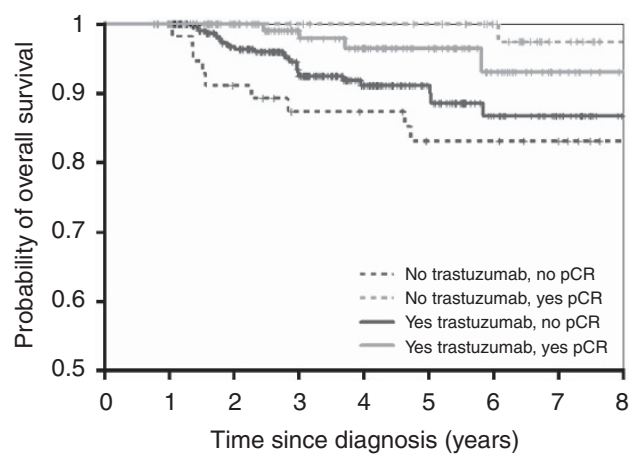

Group Number of patients at risk

$\begin{array}{llllllllll}\text { No Tras, no pCR } & 56 & 56 & 50 & 45 & 43 & 38 & 38 & 35 & 31\end{array}$

$\begin{array}{llllllllll}\text { No Tras, yes pCR } & 53 & 53 & 49 & 47 & 45 & 44 & 39 & 27 & 21\end{array}$

$\begin{array}{llllllllll}\text { Yes Tras, no pCR } & 330 & 326 & 248 & 185 & 121 & 73 & 42 & 25 & 7\end{array}$

$\begin{array}{lllllllll}\text { Yes Tras, yes pCR } & 150 & 150 & 115 & 83 & 62 & 44 & 24 & 11\end{array}$
B

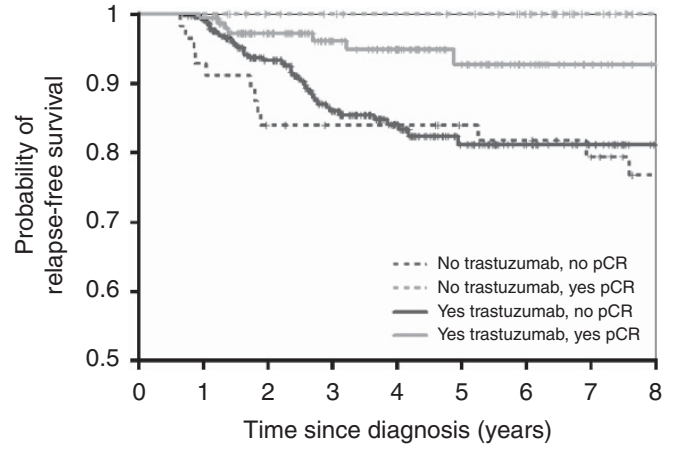

Group Number of patients at risk

$\begin{array}{llllllllll}\text { No Tras, no pCR } & 56 & 56 & 50 & 45 & 43 & 38 & 38 & 35 & 31\end{array}$ $\begin{array}{llllllllll}\text { No Tras, yes pCR } & 53 & 53 & 49 & 47 & 45 & 44 & 39 & 27 & 21\end{array}$ $\begin{array}{llllllllll}\text { Yes Tras, no pCR } & 330 & 326 & 248 & 185 & 121 & 73 & 42 & 25 & 7\end{array}$ Yes Tras, yes pCR $150 \quad 150 \quad 115 \quad 83 \quad 62 \quad 44 \quad 24 \quad 11 \quad 4$

Figure 1. Kaplan-Meier OS estimates (A) and RFS estimates (B) according to adjuvant trastuzumab use and pCR status. 
Table 3. Multivariable Cox proportional hazards models

\begin{tabular}{|l|c|c|c|c|c|c|}
\cline { 2 - 6 } \multicolumn{2}{c|}{} & \multicolumn{3}{c|}{ Overall survival } & \multicolumn{3}{c|}{ Relapse-free survival } \\
\cline { 2 - 6 } & Hazard ratio & $95 \%$ Cl & P-value & Hazard ratio & $95 \%$ Cl & $P$-value \\
\hline Adjuvant trastuzumab vs no & 0.75 & $0.31-1.78$ & 0.51 & 1.1 & $0.52-2.33$ & 0.81 \\
\hline Year of diagnosis: 2001-2006 vs 2007-2012 & 0.78 & $0.34-1.79$ & 0.56 & 1.13 & $0.59-2.17$ & 0.72 \\
\hline pCR vs no & 0.23 & $0.08-0.6$ & 0.003 & 0.22 & $0.1-0.49$ & 0.0002 \\
\hline Back race vs other & 1.37 & $0.56-3.33$ & 0.49 & 2.07 & $1.11-3.87$ & 0.022 \\
\hline Clinical stage III vs I and II & 1.42 & $0.71-2.84$ & 0.32 & 2.28 & $1.3-3.99$ & 0.004 \\
\hline Hormone receptor positive vs negative. & 1.48 & $0.54-4.05$ & 0.45 & 1.45 & $0.63-3.33$ & 0.38 \\
\hline Lymphovascular invasion vs no & 2.17 & $1.06-4.45$ & 0.034 & 2.28 & $1.33-3.93$ & 0.003 \\
\hline Adjuvant endocrine therapy vs no & 0.37 & $0.14-1.02$ & 0.05 & 0.57 & $0.25-1.28$ & 0.17 \\
\hline Abbreviation: Cl=confidence interval. & & & & \\
\hline
\end{tabular}

caution, but they support the concept that patients achieving a pCR may not receive further benefit from adjuvant anti-HER2 therapy and therefore, toxicities may be avoided. Furthermore, if patients achieving a pCR do not receive further benefit from adjuvant trastuzumab, this could have important implications associated with resource optimisation. This is particularly relevant as the use of double anti-HER2 blockade becomes standard in the neoadjuvant setting and we increase the rates of pCR. Further prospective studies are needed to evaluate the impact of continued HER2 therapy among patients with a pCR. In addition, ongoing prospective studies evaluating the benefit of adjuvant anti-HER2 therapies after a pCR would be ideal to answer this important question and an opportunity for comparative effectiveness research, particularly as we incorporate newer targeted therapies into the care of our patients (Pritchard, 2010).

\section{ACKNOWLEDGEMENTS}

This work was supported in part by American Cancer Society Research Scholar Grant 121329-RSG-11-187-01-TBG (AMG) and The Commonwealth Foundation for Cancer Research (AMG). DHHS-NIH-National Cancer Institute: 2P30 CA016672 (PP-RP6) Cancer Center Support grant to MD Anderson Cancer Center. The MD Anderson Breast Cancer Management is supported in part by the Nelly B. Connally Breast Cancer Research Fund.

\section{CONFLICT OF INTEREST}

GNH, VV, and AMG have received research funding from Genentech and GSK. All remaining authors have declared no conflicts of interest.

\section{REFERENCES}

Baselga J, Bradbury I, Eidtmann H, Di Cosimo S, de Azambuja E, Aura C, Gómez H, Dinh P, Fauria K, Van Dooren V, Aktan G, Goldhirsch A, Chang TW, Horváth Z, Coccia-Portugal M, Domont J, Tseng LM, Kunz G, Sohn JH, Semiglazov V, Lerzo G, Palacova M, Probachai V, Pusztai L, Untch M, Gelber RD, Piccart-Gebhart M. NeoALTTO Study Team (2012) Lapatinib with trastuzumab for HER2-positive early breast cancer (NeoALTTO): a randomised, open-label, multicentre, phase 3 trial. Lancet 379(9816): 633-640.

Bayraktar S, Gonzalez-Angulo AM, Lei X, Buzdar AU, Valero V, Melhem-Bertrandt A, Kuerer HM, Hortobagyi GN, Sahin AA, Meric-Bernstam F (2012) Efficacy of neoadjuvant therapy with trastuzumab concurrent with anthracycline- and nonanthracycline-based regimens for HER2-positive breast cancer. Cancer 118(9): 2385-2393.
Buzdar AU, Ibrahim NK, Francis D, Booser DJ, Thomas ES, Theriault RL, Pusztai L, Green MC, Arun BK, Giordano SH, Cristofanilli M, Frye DK, Smith TL, Hunt KK, Singletary SE, Sahin AA, Ewer MS, Buchholz TA, Berry D, Hortobagyi GN (2005) Significantly higher pathologic complete remission rate after neoadjuvant therapy with trastuzumab, paclitaxel, and epirubicin chemotherapy: results of a randomized trial in human epidermal growth factor receptor 2-positive operable breast cancer. J Clin Oncol 23(16): 3676-3685.

Buzdar AU, Suman VJ, Meric-Bernstam F, Leitch AM, Ellis MJ, Boughey JC, Unzeitig G, Royce M, McCall LM, Ewer MS, Hunt KK. American College of Surgeons Oncology Group, investigators (2013) Fluorouracil, epirubicin, and cyclophosphamide (FEC-75) followed by paclitaxel plus trastuzumab versus paclitaxel plus trastuzumab followed by FEC-75 plus trastuzumab as neoadjuvant treatment for patients with HER2-positive breast cancer (Z1041): a randomised, controlled, phase 3 trial. Lancet Oncol 14(13): 1317-1325.

Buzdar AU, Valero V, Ibrahim NK, Francis D, Broglio KR, Theriault RL, Pusztai L, Green MC, Singletary SE, Hunt KK, Sahin AA, Esteva F, Symmans WF, Ewer MS, Buchholz TA, Hortobagyi GN (2007) Neoadjuvant therapy with paclitaxel followed by 5 -fluorouracil, epirubicin, and cyclophosphamide chemotherapy and concurrent trastuzumab in human epidermal growth factor receptor 2-positive operable breast cancer: an update of the initial randomized study population and data of additional patients treated with the same regimen. Clin Cancer Res 13(1): 228-233.

Cortazar P, Zhang L, Untch M, Mehta K, Costantino JP, Wolmark N, Bonnefoi H, Cameron D, Gianni L, Valagussa P, Swain SM, Prowell T, Loibl S, Wickerham DL, Bogaerts J, Baselga J, Perou C, Blumenthal G, Blohmer J, Mamounas EP, Bergh J, Semiglazov V, Justice R, Eidtmann H, Paik S, Piccart M, Sridhara R, Fasching PA, Slaets L, Tang S, Gerber B, Geyer Jr CE, Pazdur R, Ditsch N, Rastogi P, Eiermann W, von Minckwitz G (2014) Pathological complete response and long-term clinical benefit in breast cancer: the CTNeoBC pooled analysis. Lancet 384(9938): 164-172. Firth D (1993) Bias reduction of maximum likelihood estimates. Biometrika 80(1): 27-38.

Fisher B, Bryant J, Wolmark N, Mamounas E, Brown A, Fisher ER, Wickerham DL, Begovic M, DeCillis A, Robidoux A, Margolese RG, Cruz Jr AB, Hoehn JL, Lees AW, Dimitrov NV, Bear HD (1998) Effect of preoperative chemotherapy on the outcome of women with operable breast cancer. J Clin Oncol 16(8): 2672-2685.

Gianni L, Eiermann W, Semiglazov V, Lluch A, Tjulandin S, Zambetti M, Moliterni A, Vazquez F, Byakhov MJ, Lichinitser M, Climent MA, Ciruelos E, Ojeda B, Mansutti M, Bozhok A, Magazzù D, Heinzmann D, Steinseifer J, Valagussa P, Baselga J (2014) Neoadjuvant and adjuvant trastuzumab in patients with HER2-positive locally advanced breast cancer (NOAH): follow-up of a randomised controlled superiority trial with a parallel HER2-negative cohort. Lancet Oncol 15(6): 640-647.

Gianni L, Pienkowski T, Im YH, Roman L, Tseng LM, Liu MC, Lluch A, Staroslawska E, de la Haba-Rodriguez J, Im SA, Pedrini JL, Poirier B, Morandi P, Semiglazov V, Srimuninnimit V, Bianchi G, Szado T, Ratnayake J, Ross G, Valagussa P (2012) Efficacy and safety of neoadjuvant pertuzumab and trastuzumab in women with locally advanced, inflammatory, or early HER2-positive breast cancer (NeoSphere): a randomised multicentre, open-label, phase 2 trial. Lancet Oncol 13(1): 25-32. 
Goldhirsch A, Gelber RD, Piccart-Gebhart MJ, de Azambuja E, Procter M, Suter TM, Jackisch C, Cameron D, Weber HA, Heinzmann D, Dal Lago L, McFadden E, Dowsett M, Untch M, Gianni L, Bell R, Köhne CH, Vindevoghel A, Andersson M, Brunt AM, Otero-Reyes D, Song S, Smith I, Leyland-Jones B, Baselga J. Herceptin Adjuvant Trial Study Team (2013) 2 years versus 1 year of adjuvant trastuzumab for HER2-positive breast cancer (HERA): an open-label, randomised controlled trial. Lancet 382(9897): 1021-1028.

Gralow JR, Burstein HJ, Wood W, Hortobagyi GN, Gianni L, von Minckwitz G, Buzdar AU, Smith IE, Symmans WF, Singh B, Winer EP (2008) Preoperative therapy in invasive breast cancer: pathologic assessment and systemic therapy issues in operable disease. J Clin Oncol 26(5): 814-819.

Joensuu H, Bono P, Kataja V, Alanko T, Kokko R, Asola R, Utriainen T, Turpeenniemi-Hujanen T, Jyrkkiö S, Möykkynen K, Helle L, Ingalsuo S, Pajunen M, Huusko M, Salminen T, Auvinen P, Leinonen H, Leinonen M, Isola J, Kellokumpu-Lehtinen PL (2009) Fluorouracil, epirubicin, and cyclophosphamide with either docetaxel or vinorelbine, with or without trastuzumab, as adjuvant treatments of breast cancer: final results of the FinHer Trial. J Clin Oncol 27(34): 5685-5692.

Kim MM, Allen P, Gonzalez-Angulo AM, Woodward WA, Meric-Bernstam F, Buzdar AU, Hunt KK, Kuerer HM, Litton JK, Hortobagyi GN, Buchholz TA, Mittendorf EA (2013) Pathologic complete response to neoadjuvant chemotherapy with trastuzumab predicts for improved survival in women with HER2-overexpressing breast cancer. Ann Oncol 24(8): 1999-2004.

Pivot X, Romieu G, Debled M, Pierga JY, Kerbrat P, Bachelot T, Lortholary A, Espié M, Fumoleau P, Serin D, Jacquin JP, Jouannaud C, Rios M, Abadie-Lacourtoisie S, Tubiana-Mathieu N, Cany L, Catala S, Khayat D, Pauporté I, Kramar A. PHARE trial investigators (2013) 6 months versus 12 months of adjuvant trastuzumab for patients with HER2-positive early breast cancer (PHARE): a randomised phase 3 trial. Lancet Oncol 14(8): 741-748.
Pritchard KI (2010) Optimizing the delivery of targeted research: an opportunity for comparative effectiveness research. J Clin Oncol 28(7): 1089-1091.

Takada M, Ishiguro H, Nagai S, Ohtani S, Kawabata H, Yanagita Y, Hozumi Y, Shimizu C, Takao S, Sato N, Kosaka Y, Sagara Y, Iwata H, Ohno S, Kuroi K, Masuda N, Yamashiro H, Sugimoto M, Kondo M, Naito Y, Sasano H, Inamoto T, Morita S, Toi M (2014) Survival of HER2positive primary breast cancer patients treated by neoadjuvant chemotherapy plus trastuzumab: a multicenter retrospective observational study (JBCRG-C03 study). Breast Cancer Res Treat 145(1): 143-153.

Untch M, Fasching PA, Konecny GE, Hasmuller S, Lebeau A, Kreienberg R, Camara O, Müller V, du Bois A, Kühn T, Stickeler E, Harbeck N, Höss C, Kahlert S, Beck T, Fett W, Mehta KM, von Minckwitz G, Loibl S (2011) Pathologic complete response after neoadjuvant chemotherapy plus trastuzumab predicts favorable survival in human epidermal growth factor receptor 2-overexpressing breast cancer: results from the TECHNO trial of the AGO and GBG study groups. J Clin Oncol 29(25): 3351-3357.

Wolff AC, Hammond ME, Hicks DG, Dowsett M, McShane LM, Allison KH, Allred DC, Bartlett JM, Bilous M, Fitzgibbons P, Hanna W, Jenkins RB, Mangu PB, Paik S, Perez EA, Press MF, Spears PA, Vance GH, Viale G, Hayes DF. American Society of Clinical Oncology; College of American Pathologists (2013) Recommendations for human epidermal growth factor receptor 2 testing in breast cancer: American Society of Clinical Oncology/ College of American Pathologists clinical practice guideline update. J Clin Oncol 31(31): 3997-4013.

This work is published under the standard license to publish agreement. After 12 months the work will become freely available and the license terms will switch to a Creative Commons AttributionNonCommercial-Share Alike 4.0 Unported License. 